\title{
Parceria do Estado com ONGs/AIDS: crítica ao padrão emergente de intervenção social
}

\section{State partnership with NGOs/SIDA: review to the emerging pattern of social intervention}

\author{
Valéria Bastos Gomes ${ }^{1}$, José Jackson Coelho Sampaio² ${ }^{2}$ Erasmo Miessa Ruiz ${ }^{3}$, Taís Bleicher ${ }^{4}$, Heraldo Simões Ferreira ${ }^{5}$, \\ Frederico Emmanuel Leitão Araújo ${ }^{6}$, Mariana Ramalho de Farias ${ }^{4}$
}

1. Doutoranda em Saúde Coletiva pela associação ampla UFC/UECE/UNIFOR. 2. Doutor em medicina preventiva pela Universidade de São Paulo/
Ribeirão Preto - USP. Psiquiatra. Professor Titular da Universidade Estadual do Ceará. 3. Doutor em Educação pela Universidade Federal do Ceará-
UFC. Psicólogo. Professor Adjunto da Universidade Estadual do Ceará. 4. Doutoranda em Saúde Coletiva pela associação ampla UFC/UECE/UNIFOR.
Psicóloga clínica da UFC. 5. Doutor em Saúde Coletiva pela associação ampla UFC/UECE/UNIFOR. Professor Adjunto da Universidade Estadual do Ceará. 6. Mestre em Saúde Publica pela UECE. Professor Substituto do Curso de Medicina da UECE.

\section{Resumo}

Introdução: A reforma do Estado, iniciada na década de 1990, repassa responsabilidades sociais para o setor público-não estatal, onde são alocadas diversas entidades do terceiro setor, como as Organizações Não Governamentais. Nesse contexto, analisam-se as concepções dos formuladores de políticas de saúde acerca das parcerias ONGs/Aids no Ceará, por meio de metodologia qualitativa. Métodos: A pesquisa ocorreu na Secretaria da Saúde do Estado do Ceará, SESA/Ce, em Fortaleza-Ceará, no período de janeiro a março de 2006. Foram realizadas entrevistas com três gestores estaduais: Coordenadora das políticas de saúde, Coordenadora das políticas de DST/Aids e representante do Secretário de Saúde do Estado. As entrevistas foram analisadas pela técnica da análise de discurso. Resultados: Os resultados indicam que os gestores consideram as parcerias com as ONGs/ Aids imprescindíveis, pois o Estado tem deficiência de comunicação com os segmentos da sociedade considerados mais vulneráveis. Eles apontam a falta de preparação dos profissionais da Secretaria da Saúde para realizarem trabalho de prevenção e promoção junto a tais populações. Nesse caso, a participação das ONGs/Aids nas políticas de prevenção às DST/Aids tem caráter complementar e não substitutivo do papel do Estado. Na prática, porém, ficou evidente a transferência, não a complementaridade, e problemas na regulação pública das ações e recursos financeiros transferidos, pois a mesma é frágil e o monitoramento das atividades das ONGs, pelo Estado, seria insuficiente. Conclusão: Conclui-se que os formuladores percebem as deficiências estatais e preconizam a parceria com as ONGs como virtual solução para as problemáticas apontadas, se mantidas a lógica da complementaridade e a competência reguladora.

Palavras-chave: Estado. Políticas Públicas de Saúde. Organizações não Governamentais.

\begin{abstract}
Background: With the State Reform which took place in the 1990's, its social responsibilities were handed over to the non-State public sector. In it, many entities of the third sector are allocated, like the Non-Governmental Organizations. Therefore, we tried to understand the conceptions of the formulators of health policies about NGOs/Aids partnerships in Ceará. Methods: The qualitative methodology was employed. The research was conducted at the Ceará Department of Health, SESA/Ce, from January to March 2006. Three interviews were conducted with State managers: health policies coordinator, STD/Aids policies coordinator and the State Health Secretary representative. The speeches were analyzed through the discourse analysis technique. Results: showed that managers consider the partnerships with NGOs/Aids indispensable, because the State has deficiencies in the communication within the society segments considered most vulnerable. They point out the lack of qualification of the professionals from the Health department conducting prevention and promotion work with such populations. To these formulators, the participation of the NGOs/Aids in STD/Aids prevention policies has only a complementary nature and it's not a State substitute. In practice, however, the transference was clear, but not the complementariness, and the problems in the public regulation of actions and transferred financial resources, for it is fragile and the monitoring, by the State, of the actions of these organizations would be inoperative. Conclusion: It's concluded that the formulators notice the State deficiencies as apparently insoluble in its own ambit, foreseeing the partnership with the NGOs as a virtual solution to the problems mentioned, if kept the logics of complementariness and the regulatory competence.
\end{abstract}

Keywords: State. Health Public Policy. Non-Governmental Organizations.

Correspondência: Rua Carlos Vasconcelos, 2459, apto. 401, Aldeota. Fortaleza-Ceará. E-mail: vcbstar@gmail.com Conflito de interesses: Não houve conflitos de interesse na realização do presente estudo.

Recebido em 24 Set 2013; Revisado em 20 Nov 2013; Aceito em 29 Nov 2013. 


\section{INTRODUÇÃO}

A expressão terceiro setor engloba as Organizações Não Governamentais (ONG), as Fundações, as Associações, as Organização da Sociedade Civil de Interesse Público (OSCIP), Organizações Sociais (OS), entidades registradas como "sem fins lucrativos" e Organizações da Sociedade Civil-OSC.

Sob a regência do Fundo Monetário Internacional (FMI) e do Banco Mundial, a América Latina é orientada a seguir um receituário político-econômico conforme as orientações denominadas de Consenso de Washington, que propõe a retomada do desenvolvimento econômico por meio das seguintes linhas de ação: globalização econômica, redução das ações estatais e privatização de serviços. A Reforma do Estado constitui, portanto, eixo fundamental do processo, donde ser preconizado um ordenamento que estabeleça novas formas de articulação entre o Estado e a Sociedade Civil, corresponsabilizando a Sociedade Civil, por meio do terceiro setor, destaque para as ONGs, na execução das políticas públicas.

Faz-se necessário, para compreender o processo, remeterse à gênese das ONGs no Brasil e sua inserção nas políticas de saúde. Essas entidades surgiram nas décadas 1950/60, com existência quase clandestina, ligadas às igrejas e aos movimentos sociais, sindicais e populares, executando tarefas de assessoria e consultoria. Nesse período, a presença dessas organizações inscrevia-se no esforço de luta contra o regime militar e pela redemocratização do país ${ }^{2}$. Mas, a tarefa, dos anos 1980 aos dias de hoje, tem consistido na descentralização das políticas públicas de saúde, educação, previdência e assistência, para um setor privado constituído como de interesse público.

Oconflitoentreapropostadiscursiva da corresponsabilização Estado/Sociedade nas políticas públicas, sobretudo nas políticas de saúde, e a prática efetiva de desreponsabilidade do Estado no tocante à proteção social constitui o problema em questão.

Em 1980, em virtude do aparecimento da epidemia da Aids e da especulação midiática sobre a chegada de uma doença denominada de "câncer gay" ou "peste gay", observou-se avançar no país vários movimentos sociais decorrentes. Os mesmos contribuíram para criar em São Paulo, em 1985, a primeira ONG/Aids brasileira, o Grupo de Apoio e Prevenção à Aids de São Paulo-GAPA/SP.

A Coordenação Estadual de DST/Aids do Ceará, instalada pela Secretaria Estadual de Saúde (SESA), começou a articular-se com as ONGs/Aids, desde 1989, antes mesmo que o Ministério da Saúde acenasse para tais parcerias, via financiamento do Banco Mundial, iniciado em 1994. Em consonância com a orientação do Programa Nacional de DST/Aids, a SESA/Ce já elaborara dois Planos Operativos Anuais, o POA I e o POA II, visando à articulação cooperativa e a captação de projetos a serem desenvolvidos pelas ONGs/ Aids, sem predefinição dos percentuais a serem alocados para cada entidade. Após a aprovação da lei do Terceiro
Setor e em acordo com a norma sobre a transferência de recursos fundo a fundo, na forma de incentivo ${ }^{3}$, a Portaria 2.313, de 19 de dezembro de 2002, estabelece a obrigatoriedade de repassar $10 \%$ do total de recursos dos planos estaduais para as ONGs/Aids.

No Ceará, cerca de trinta ONGs/Aids receberam recursos dos planos DST/Aids para desenvolver trinta e sete projetos, no período de doze meses, com valor na ordem de $R \$ 1.695 .704,22^{4}$. A situação foi extraordinária, pois o Orçamento Geral da União não previa percentual específico para o Setor Saúde. Apenas hoje, depois de muitas lutas, conseguiu-se aprovar $12 \%$ da receita tributária para os governos estaduais destinarem ao setor saúde ${ }^{5}$.

A reflexão sobre a temática permitiu formular uma hipótese primária, genérica, adequada aos estudos analíticos, de lógica qualitativa: com a lei do Terceiro Setor o Estado transfere para o setor "público não-estatal" a execução de serviços sociais de educação, saúde, cultura e pesquisa científica, tendo as ONGs como as maiores executoras, cabendo ao Estado o papel de macrorregulador, mas o que é identificado, na prática, é a ocorrência da desresponsabilização do Estado.

A pesquisa que subsidiou o presente artigo teve por objetivo analisar as concepções dos formuladores da política da SESA/CE acerca das parcerias com as ONGs/Aids frente à política estadual de DSTs/Aids do Ceará.

\section{MÉTODOS}

A pesquisa ocorreu na Secretaria da Saúde do Estado do Ceará-SESA/CE, em Fortaleza, Ceará. As entrevistas foram realizadas no período de janeiro a março de 2006. Para nosso estudo, foi enfocada a Coordenação de Políticas de Saúde-COPOS, onde está situado o Núcleo de Normatização da Atenção à Saúde- NUNAS, por sua vez subdividido em Células, entre as quais a Célula de Atenção à Saúde Reprodutiva e Sexual, em que atuam alguns grupos técnicos, como o Viva Mulher e o DSTs/AIDS.

Foram tomados como informantes os titulares do Programa Estadual DST/Aids e da COPOS e um representante do Secretário Estadual de Saúde, codificados por pseudônimos. A coordenadora do Programa Estadual DST/Aids foi codificada como sendo entrevistada $n^{\circ}$ 01, nomeada de "Antônia" (E01Antônia); a coordenadora de Políticas de Saúde, como sendo entrevistada no 02, nomeada "Maria" (E02Maria); e o representante do Secretário Estadual de Saúde, entrevistado no 03, nomeado "Gerson" (E03Gerson). A pesquisa foi aprovada pelo Comitê de Ética da Universidade Estadual do Ceará- UECE, sob o protocolo de número 04545457-4. As entrevistas foram gravadas em aparelho cassete de áudio, depois transcritas pelo próprio pesquisador e submetidas ao processo de análise. A duração média das entrevistas foi de aproximadamente 60 minutos. 
Por ocasião da entrevista, foi aplicada uma questão disparadora: "o que você pensa sobre a parceria entre a SESA/Ce e as ONGs/Aids em relação à Política Estadual de DST/Aids?" Os textos resultantes das transcrições das gravações foram analisados segundo as técnicas de Análise do Discurso proposta por Brandão ${ }^{6}$.

\section{RESULTADOS E DISCUSSÕES}

\section{Ao Estado compete regular, não executar}

O governo, por meio do contrato de parcerias, vislumbrou a oportunidade de estabelecer ligação entre o Estado e as entidades do Terceiro Setor, em que o primeiro contrata as segundas sem as medidas rígidas previstas na Lei de n. 8.666/93, que trata de licitação, concorrência pública e transferências de dinheiro público ao setor privado.

Em 1992, a ideia de um empréstimo do Banco Mundial ao Brasil para as atividades em HIV/Aids começa a ser disseminada; no mesmo ano uma equipe do Banco vem em missão ao Brasil com o objetivo de identificar com o Ministério da Saúde as prioridades e o andamento do projeto de controle das DSTs/Aids, que já estava sendo elaborado pelos técnicos do referido Ministério. A missão esteve em Brasília, Rio de Janeiro, São Paulo, visitando Secretarias de Saúde, ONGs e serviços de saúde?

Em 1994, o acordo do empréstimo do Banco Mundial ao governo brasileiro para implementar o projeto de controle das DSTs/Aids, mais conhecido como Aids I, é firmado. Itamar Franco era o Presidente da República, Adib Jatene era o Ministro da Saúde e Lair Guerra exercia a coordenação do Programa Nacional de Aids. Apesar de o projeto ter sido firmado em 1994, data de 1993 a primeira concorrência aberta pelo Programa Nacional de Aids para receber projetos das $\mathrm{ONGs}^{8}$.

No Ceará, para a Política de DSTs/Aids, a SESA/CE fez parcerias com as ONGs/AIDS para cumprir uma ordenação do Banco Mundial. Ao Estado caberia a função reguladora, não mais executora, e isto é percebido, claramente, pelos entrevistados:

"O Estado não executa mais as políticas, ele propõe, financia e regula as políticas" (E03Gerson).

"O Estado não é mais um executor de políticas, ele é um coordenador, regulador de políticas" (E01Antônia).

"Ao Estado compete financiar e regular as políticas de saúde no campo societário" (E02Maria).

Atualmente, quem faz grande parte do trabalho de prevenção às DSTs/Aids na capital e nos municípios são as ONGs/Aids. As 35 ONGs/Aids do Estado do Ceará assumiram a tarefa de realizar a cobertura da prevenção em Fortaleza, e 12 delas assumiram também alguns municípios no interior do Estado. Não haveria obstáculo político, legal ou ideológico, se a parceria tivesse caráter complementar. Contudo, a SESA/CE tem utilizado as ONGs/ Aids para executar o trabalho de prevenção e de assistência às DSTs/Aids, como uma entrevistada percebe:

"O Estado não é mais o prestador de serviço, ele agora é apenas o regulador dos serviços feitos pelas ONGs..." (EO2Maria).

A SESA/CE abre licitação, contrata as ONGs, e as mesmas executam trabalhos de prevenção, assistência e apoio aos públicos-alvos. Lentamente, a partir de demandas iniciais respaldadas na competência específica em lidar com "segmentos vulneráveis", elas passaram a responder pelas ações. E os "vulneráveis" foram ampliados, conforme se verificou na pesquisa: dos iniciais de crianças, menores infratores, travestis, prostitutas, incorporaram-se idosos, motoristas de táxi, operários de construção civil, entre outros, acompanhando o comportamento da epidemia e as ressignificações do conceito de vulnerabilidade.

Contraditoriamente, apesar do discurso da parceria parecer unificado, encontramos na fala de alguns formuladores, contradições com relação ao papel do Estado, no tocante à prevenção às DSTs/Aids.

"O Estado tem que cumprir mais o seu papel, o papel de executor mesmo, de fato (...) As ONGs teriam um papel regulador, papel fiscalizador desse processo, seria um papel menos operativo" (E01Antônia).

“O Estado é um prestador de serviço de saúde, ele também deve trabalhar com prevenção [Agora] não está escrito em nenhum lugar que fazer prevenção é um papel exclusivo do Estado" (E03Gerson).

Essa nova modalidade de gestão é ancorada no modelo neoliberal, segundo os quais organismos privados, embora sem fins lucrativos, assumem responsabilidades do Estado e constituem nova forma de enfrentamento das questões sociais ${ }^{9}$. Mas, a percepção desses fatos não é homogênea. Os próprios atores concordam, discordam e se contradizem. Há uma luta entre percepções, opiniões, concepções e interesses, ainda de modo muito agudo.

\section{A regulação pelo Estado, na prática, é frágil}

A reforma empreendida apresentou ao Estado um problema socioeconômico e político: transferir papéis do Estado para instituições da sociedade civil. Em seguida, um problema de planejamento, o desafio da macrorregulação. Por fim, um problema de gestão, pelo desafio técnico-operacional. Para os gestores, a parceria é necessária e bem sucedida, nos seus fins, restando como problema à fragilidade do Estado no que diz respeito à regulação das instituições privadas, com ou sem fins lucrativos: 
"As parcerias são importantíssimas, o problema é que nessa área de macro regulação, o Estado é frágil, temos muita deficiência nessa área. Não temos instrumentos e não temos pessoal qualificado para exercer essas atividades" (E02Maria).

"Eu estou dizendo que o Estado, para aumentar a parceria com o terceiro setor, tem que crescer o aparelho de acompanhamento e fiscalização. O estado que não tem essa capacidade, não consegue fazer avaliação do que está se passando no setor privado, se há ou não melhor resultado que quando executado por ele. Nós estamos passando um recurso financeiro para ONGs, acreditando que elas são capazes de fazer mais e melhor, porém não sabemos se o objetivo foi alcançado" (E01Antônia).

"O Estado, ainda carece de uma função macroregulatória eficiente e bem desenvolvida para fiscalizar melhor as ações das entidades privadas com ou sem fins lucrativos" (E01Antônia).

Foi nessa perspectiva que, em 2001, foi criada, na SESA, o Núcleo de Normatização da Atenção à Saúde Sexual e Reprodutiva-NUNAS, para realizar o monitoramento e a avaliação das ONGs/Aids que recebiam recursos diretamente do Ministério da Saúde.

Como reflexo desse processo, observou-se pela leitura de leis, normas, projetos, relatórios e jornais publicados regularmente que a Política Nacional de Prevenção às DSTs/ Aids delegou para as ONGs/Aids realizarem os trabalhos de prevenção e de assistência, cabendo às Secretarias Estaduais de Saúde o monitoramento físico-financeiro, o acompanhamento e a avaliação, por meio de estudos e de visitas in loci, institucionalizando-se, gradativamente, dispositivos de acompanhamento

"A macro função de regulação pelo Estado é muito pequena, porque ele (Estado) não tem mecanismo regulatório hábil. Aí nós ficamos na mão dessas instituições, mas já aparecem saídas" (E01Antônia).

Assim, estamos diante de alguns problemas: Um deles se refere ao Estado não estar capacitado, instrumentalizado, para fazer o devido controle e monitoramento das ações e dos recursos destinados às ONGs/Aids.

Outra situação foi sendo gestada: se o Estado não está habilitado para exercer sua função de macrorregulação sobre tais entidades, se a sociedade civil não faz parte do processo de controle e não há espaço para ela nessa nova modalidade de gestão, quem assumirá o controle social das políticas de saúde?

Pela lógica não intervencionista-estatal da perspectiva neoliberal, o Estado realiza sua 'proteção social' por meio das ONGs, então o Estado se fragiliza, e a sociedade civil não assume o controle, portanto não são criados dispositivos de nova natureza. A nova modalidade de gestão faz desaparecer a visibilidade das Conferências nacionais, estaduais e municipais de saúde e dos Conselhos nacionais, estaduais, municipais e locais de saúde. Como compatibilizar o preceito constitucional e os dispositivos de democracia participativa do SUS com a multiplicação de organismos privados, embora não formalmente lucrativos?

Ao promover a redução do Estado mediante mecanismos de descentralização, transferência funcional e privatização, as políticas públicas, mormente nas economias periféricas, perdem organicidade e potência ${ }^{10}$. Uma das consequências dessas perdas teria clara consequência econômica e política, qual seja, a crescente transferência de recursos públicos para a gestão privada de seus fins. O que pode estar ocorrendo é uma transferência de recursos e atribuições para as organizações não governamentais, com insipiente controle do poder público.

Não podemos afirmar que os objetivos propostos nos projetos de intervenção dessas entidades estão sendo executados com eficiência e diligência, pois, há uma supressão de instrumentos regulatórios adequados que avaliem e monitorem a eficácia das ações financiadas. De acordo com Santos ${ }^{11}$ (2002), a pretensão de driblar o burocratismo estatal e a rigidez no exercício de políticas públicas estão resultando em facilitação para a transferência de recursos financeiros públicos para entidades privadas, lucrativas ou não, componentes do terceiro setor.

Esses achados apresentam verossimilhança com a literatura crítica sobre o terceiro setor, conforme Nogueira ${ }^{12}$ : os principais resultados do reformismo vitorioso nos anos 90 foram, portanto, a desvalorização do Estado aos olhos da sociedade e a própria desorganização de seu aparato técnico, regulatório e administrativo.

\section{O trabalhador da saúde, em função pública, não consegue dialogar com grupos "vulneráveis"}

Pode-se dizer que, em virtude do discurso da inoperância da regulação do Estado sobre tais organismos privados sem fins lucrativos, igualmente, constituiu-se uma "cultura de consenso" em relação à atuação do Estado em face de alguns segmentos da sociedade. Exemplifica-se na cultura disseminada que o Estado, nas suas três instâncias de governo, não teria condições de intervenção em alguns grupos, como os de profissionais do sexo, de homossexuais e de usuários de drogas.

O centro da argumentação é a falta de habilidade, derivada da modalidade de formação do trabalhador da saúde, sobretudo daqueles que passam a atuar na atenção básica. Porém, os gestores não parecem crer que treinamento resolveria o problema. Ora, a reestruturação de todo o organograma daSESA/Ce, com a revisão de todas as funções, no âmbito de cujo movimento se cria o NUNAS, resultou na aplicação pensada e competente dos princípios da 
redução do Estado. A formação inadequada do trabalhador da saúde parece discurso justificativo a posteriori, pois, esse caso exemplar, da reforma da SESA/Ce, é percebido pelos entrevistados como algo de ordem macropolítica e com discursos cristalizados a favor da suposta eficiência de comunicação entre as ONGS e os segmentos "vulneráveis":

"Uma área em que o Estado ainda é frágil é na informação e comunicação com a sociedade. As ONGs se comunicam melhor com a sociedade, elas têm muito mais facilidade de comunicação que o Estado. (...) Essa área é de atenção básica, notadamente, e mesmo os profissionais que trabalham nessa área não estão qualificados para o desenvolvimento de promoção $e$ prevenção à saúde numa abordagem de educação em saúde" (E02Maria).

"O nosso enfermeiro, o nosso médico, o nosso dentista, que estão aqui dentro dessa estrutura, eles têm pouca qualificação para fazer esse tipo de abordagem" (EO3Gerson).

"Eu acho que o trabalho das ONGs é importante, porque elas conseguem chegar mais perto desses grupos do que os próprios profissionais de saúde, que não vivem e não conhecem o contexto cultural dessas populações. No caso do trabalho com travesti, quem melhor para trabalhar com travesti que eles próprios, essa, por exemplo, é uma população que não tem um acesso muito fácil ao Estado" (E01Antônia).

Desse modo, consolida-se a cultura do consenso sobre a deficiência do Estado em relação à violência de gênero, abuso de drogas e demandas sanitárias envolvendo comportamentos sexuais:

"Os profissionais nunca vão ter a capacidade, e vão ter, talvez eu esteja subestimando os profissionais. Nunca vão falar com tanta propriedade com alguns grupos, como as ONGs, porque aí estão envolvidos muitas questões pessoais, de sexualidade e de subjetividade" (E01Antônia).

"Essas dificuldades vão sempre acontecer por mais que se capacitem os profissionais de saúde, elas vão acontecer em algum momento" (EO2Maria).

Os discursos parecem cristalizados na denúncia das deficiências da interferência do Estado, sobretudo no que diz respeito às políticas sensíveis, inclusivas da subjetividade, que necessitam de adesão individual e mudanças de comportamento. O que se pode constatar é, também, outra transferência: a deficiência estatal nas áreas de prevenção e assistência deriva da formação dos profissionais de saúde, mas a solução não estaria na reformulação da formação, e, sim, na repassagem dos serviços ao Terceiro Setor, que vai atuar com profissionais de saúde formados nos mesmos projetos pedagógicos nos quais são formados os trabalhadores públicos.

Não se pode fazer uma reflexão sobre as políticas de saúde, usando como base de sustentação os profissionais de saúde, como se todo o problema residisse no âmbito apenas da atuação desses servidores. O problema aloca-se numa dimensão macropolítica, teria que se pensar numa reversão do modelo econômico e do modelo político, exatamente na raiz dos modos como se produz e se distribui riqueza, se produz e se distribui poder.

Nogueira ${ }^{13}$ sinaliza que "As políticas sociais do governo permanecem subordinadas às diretrizes seguidas na gestão econômica e financeira". A questão social permanece intocada, mal abordada, isolada, entregue a si própria, seja exercida pelo Estado, pelo Mercado ou pelas Organizações das Sociedades Civis via ONGs.

No que diz respeito à atuação dessas entidades na esfera da subjetividade e do diálogo com os segmentos "vulneráveis", pode-se inferir que não são avaliados os desempenhos a médio e longo prazo da competência alternativa das ONGs em matéria de política sensível, o que justificaria sua vantagem frente ao desempenho do Estado. Por meio de contratos de seis ou doze meses, seguidos de relatórios e novas decisões de contratos de curto prazo, avalia-se apenas o desempenho imediato, a realização formal dos objetivos e metas contratados, sem perspectiva de acompanhamento dos impactos no comportamento social a médio e longo prazo.

Tem-se a proliferação de projetos com o objetivo de atingir diferentes "públicos-alvo", contudo, são projetos desvinculados societários dentro de uma dimensão macropolítica. A literatura crítica examina: "Caímos no reino do minimalismo, onde pequenas soluções são mostradas por meio de grandes exemplos pelo governo e pela mídia" ${ }^{14}$.

Do ponto de vista das limitações do estudo, destacam-se alguns aspectos pertinentes. Não foi possível abranger um maior número de gestores e formuladores para conhecer em amplitude suas concepções acerca da parceria do Estado e as ONGs/Aids, pois o estudo se propôs, tão somente, a destacar dentro de uma perspectiva crítica, as parcerias das ONGs/Aids com o Estado e as políticas de saúde sob a égide do modelo econômico em vigor. Não foi possível, portanto, apontar outros aspectos, tais como as missões das entidades, as bandeiras de luta e as concepções dos próprios gestores e coordenadores dessas entidades acerca das parcerias do Estado com o terceiro setor e mais especificamente com a ONGs.

Por fim, pelos limites do próprio objetivo do estudo, não foi possível mencionar o Fórum de ONGs/Aids, a interface política e de articulação dessas ONGs com outras ONGs atuantes visando à realização de outras políticas sociais, e à própria relação dessas ONGs com o Mercado. 


\section{CONSIDERAÇÕES FINAIS}

Para os formuladores de políticas de saúde da SESA/CE, no período estudado, a parceria com as ONGs/Aids era importante, pois consideravam o Estado insipiente na área da informação e da comunicação com alguns segmentos societários, bem como para o exercício de políticas que envolvem conduta, comportamento e subjetividade.

Os gestores divergiam nos motivos e nas soluções, mas convergiam na afirmação da inoperância do Estado, em determinadas áreas, justificando a necessidade de complementação das responsabilidades públicas por meio da parceria com o Terceiro Setor.

Foi possível o mapeamento de alguns problemas resultantes do processo experimentado: a transferência de responsabilidades do Estado, em vez de complementação; a invisibilidade das competências de Conferências e Conselhos, dispositivos do SUS; a falha no processo de monitoramento e controle, não assumido pela sociedade civil; e a falta de instrumentos adequados à avaliação do impacto dos projetos na sociedade, dado o curto período de realização dos projetos e dos contratos. As avaliações quantitativas, quase sempre, são questionáveis para analisar transformações sociais mais profundas e de longo prazo.
Apontou-se a necessidade de serem criados mecanismo de abertura à participação popular junto às ONGs/Aids, ou seja, estimular o debate e as decisões nos segmentos sociais que trabalham. Instigou-se a ideia de estimular o controle social no âmbito das ONGs/Aids.

Estas conclusões corroboram Montaño ${ }^{15}$ : o objetivo de retirar do Estado a responsabilidade de intervenção na questão social e de transferi-las para o Terceiro Setor não ocorre por motivos de eficiência, pois as ONGs não são, necessariamente, mais eficientes que o Estado ou usam os mesmos trabalhadores; nem por motivos econômicofinanceiros, pois os custos são acrescidos de taxas contratuais; as razões são fundamentalmente político-ideológicas.

A expectativa é que o presente artigo possa oferecer uma contribuição política e social para os diferentes segmentos da sociedade acerca do papel do Estado e sua relação com as ONG's, desvendando os motivos mais concretos para a transferência do papel do Estado e do Terceiro Setor nas políticas sociais sensíveis. No plano empírico, a contribuição do estudo visa equacionar o problema de competência, no trato das políticas sociais sensíveis apontados pelos gestores, e o conflito entre financiamento público e a invisibilidade das práticas perante o controle público.

\section{REFERÊNCIAS}

1. Montaño C. Terceiro setor e a questão social: crítica ao padrão emergente de intervenção social. São Paulo: Cortez; 2002.

2. Gohn G. O novo associativismo e o terceiro setor: o novo cenário da participação e da organização popular nos anos 90. Serv Soc Soc. 1999; 58:120-135.

3. Ministério da Saúde (BR). Secretaria de Política de Saúde (BR). Coordenação Nacional de DST/Aids - política de financiamento das ações em HIV/Aids para estados e municípios - Transferência fundo a fundo na forma de incentivo. Brasília - DF. Março; 2002.

4. Secretaria da Saúde do Estado do Ceará (BR). Núcleo de Saúde Sexual e Reprodutiva NUNAS/SSR. Plano de Ações e Metas DST/Aids- 2ㅇ PAM. Fortaleza; 2004/2005.

5. Silva MG. Saúde Pública: auto-avaliação e revisão. 2. ed. São Paulo: Editora Atheneu; 1997.

6. Brandão HHN. Introdução à Análise do Discurso. Campinas: UNICAMP; 1995.

7. Galvão J. Aids no Brasil: agenda de construção de uma epidemia. 1. ed. Rio de Janeiro: ABIA; São Paulo: Ed. 34; 2000. 256 p.
8. Solano N. As Organizações Não-Governamentais e a Coordenação Nacional de DST/Aids. Direitos Humanos, Cidadania e Aids. Cad ABONG. 2000; 28:75-127.

9. Montaño C. Terceiro setor e a questão social: crítica ao padrão emergente de intervenção social. São Paulo: Cortez; 2002.

10. Semeraro G. Gramsci e a Sociedade Civil: Cultura e Educação para a Democracia. 2. ed. Petrópolis: Editora Vozes; 2001.

11. Santos BS, organizador. Democratizar a democracia. Os caminhos da democracia participativa. Rio de Janeiro: Civilização Brasileira; 2002.

12. Nogueira MA. Um Estado para a sociedade civil: temas éticos e políticos da gestão democrática. São Paulo: Cortez; 2004.

13. Nogueira MA. Um Estado para a sociedade civil: temas éticos e políticos da gestão democrática. São Paulo: Cortez; 2004. p. 29.

14. Montaño C. Terceiro setor e a questão social: crítica ao padrão emergente de intervenção social. São Paulo: Cortez; 2002. p. 101.

15. Montaño C. Terceiro setor e a questão social: crítica ao padrão emergente de intervenção social. São Paulo: Cortez; 2002.

Como citar este artigo / How to cite this article:

Gomes VB, Sampaio JC, Ruiz EM, Bleicher T, Ferreira HS, Araújo FEL, de Farias MR. Parceria do Estado com ONGs/AIDS: crítica ao padrão emergente de intervenção social. J Health Biol Sci. 2013 Out-Dez; 1(4):160-165. 